\title{
A Novel Mechanism and Treatment Target for Presynaptic Abnormalities in Specific Striatal Regions in Schizophrenia
}

\author{
Vilte E Barakauskas', Clare L Beasley', Alasdair M Barr², Athena R Ypsilanti', Hong-Ying Li', \\ Allen E Thornton ${ }^{3}$, Hubert Wong ${ }^{4}$, Gorazd Rosokilja ${ }^{5,6,7}$, J John Mann ${ }^{5,6}$, Branislav Mancevski ${ }^{5,6}$, \\ Zlatko Jakovski $^{8}$, Natasha Davceva ${ }^{8}$, Boro Ilievski ${ }^{5,9}$, Andrew J Dwork ${ }^{5,6,10}$, Peter Falkai ${ }^{\prime \prime}$ \\ and William G Honer*I
}

'Department of Psychiatry, University of British Columbia, Vancouver, BC, Canada; ' ${ }^{2}$ Department of Anesthesiology, Pharmacology and Therapeutics, University of British Columbia, Vancouver, BC, Canada; ${ }^{3}$ Department of Psychology, Simon Fraser University, Burnaby, BC, Canada; ${ }^{4}$ Department of Health Care and Epidemiology, University of British Columbia, Vancouver, BC, Canada; ${ }^{5}$ Department of Molecular Imaging and Neuropathology, New York State Psychiatric Institute, New York, NY, USA; ${ }^{6}$ Department of Psychiatry, Surgeons of Columbia University, New York, NY, USA; ${ }^{7}$ Macedonian Academy of Sciences and Arts, University 'SS. Cyril and Methodius' Skopje, Macedonia; ${ }^{8}$ Institute for Forensic Medicine, University 'SS. Cyril and Methodius,', Skopje, Macedonia; 'Institute for Pathology, University 'SS. Cyril and Methodius,', Skopje, Macedonia; ${ }^{10}$ Department of Pathology and Cell Biology, College of Physicians, Surgeons of Columbia University, New York, NY, USA;

I'Department of Psychiatry, Göttingen University, Göttingen, Germany

\begin{abstract}
Abnormalities of amount and function of presynaptic terminals may have an important role in the mechanism of illness in schizophrenia. The SNARE proteins (SNAP-25, syntaxin, and VAMP) are enriched in presynaptic terminals, where they interact to form a functional complex to facilitate vesicle fusion. SNARE protein amounts are altered in the cortical regions in schizophrenia, but studies of proteinprotein interactions are limited. We extended these investigations to the striatal regions (such as the nucleus accumbens, ventromedial caudate (VMC), and dorsal caudate) relevant to disease symptoms. In addition to measuring SNARE protein levels, we studied SNARE protein-protein interactions using a novel ELISA method. The possible effect of antipsychotic treatment was investigated in parallel in the striatum of rodents that were administered haloperidol and clozapine. In schizophrenia samples, compared with controls, SNAP-25 was $32 \%$ lower $(P=0.015)$ and syntaxin was $26 \%$ lower $(P=0.006)$ in the VMC. In contrast, in the same region, SNARE protein-protein interactions were higher in schizophrenia $(P=0.008)$. Confocal microscopy of schizophrenia and control VMC showed qualitatively similar SNARE protein immunostaining. Haloperidol treatment of rats increased levels of SNAP-25 (mean 24\%, $P=0.003$ ), syntaxin (mean 18\%, $P=0.010$ ), and VAMP (mean 16\%, $P=0.00 \mathrm{I}$ ), whereas clozapine increased only the VAMP level (mean I3\%, $P=0.004$ ). Neither drug altered SNARE protein-protein interactions. These results indicate abnormalities of amount and interactions of proteins directly related to presynaptic function in the VMC in schizophrenia. SNARE proteins and their interactions may be a novel target for the development of therapeutics.

Neuropsychopharmacology (2010) 35, 1226-1238; doi:I0.1038/npp.2009.228; published online I3 January 2010
\end{abstract}

Keywords: SNAREs; schizophrenia; striatum; postmortem; protein interactions; SNAP-25

\section{INTRODUCTION}

Abnormalities of presynaptic terminals contribute to the mechanism of illness in schizophrenia (Lewis and Sweet, 2009). Postmortem studies indicate deficits in terminal numbers and in terminal-enriched molecules such as transporters and proteins involved in vesicular neurotrans-

*Correspondence: Dr WG Honer, Department of Psychiatry, UBC, University of British Columbia, Centre for Complex Disorders, A3- I27, 938 West 28 Avenue, Vancouver, BC, V5Z 4H4, Canada, Tel: + 1604 875 3664, Fax: + 1604875 387I, E-mail: honer@interchange.ubc.ca Received 30 September 2009; revised 6 November 2009; accepted 20 November 2009 mission (Harrison, 1999; Honer and Young, 2004). Current models of functional disturbances in schizophrenia emphasize disinhibitory processes, acting through GABA, glutamate, and dopamine neurotransmission to affect the firing patterns of local networks of cortical neurons (Lewis and Sweet, 2009; Lisman et al, 2008). Striatal processes are also critically important. Functional imaging provides evidence of fronto-striatal dysfunction in schizophrenia, with altered patterns of activation and impaired cognition (Manoach et al, 2000; Tost et al, 2005). Presynaptic terminals in the striatum have lower than expected levels of glutamate transporters (McCullumsmith and Meador-Woodruff, 2002; Nudmamud-Thanoi et al, 2007). Functional studies of dopaminergic presynaptic terminals carried out using 
in vivo imaging techniques indicate increased synthesis and release of dopamine in schizophrenia (Lyon et al, 2009).

Families of molecules enriched in presynaptic terminals could have important roles in these disturbances. One such family is that of SNARE proteins, SNAP-25, syntaxin, and VAMP (Söllner et al, 1993). These proteins form a trimeric complex that is vital to the mechanism of vesicular neurotransmission. Most, but not all, studies of individual SNARE proteins in the frontal cortex and hippocampus in schizophrenia indicate lower than expected levels of SNARE proteins (Fatemi et al, 2001; Gabriel et al, 1997; Halim et al, 2003; Honer et al, 2002; Honer et al, 1997; Karson et al, 1999; Mukaetova-Ladinska et al, 2002; Scarr et al, 2006; Thompson et al, 1998; Young et al, 1998). One study linked lower postmortem levels of SNAP-25 in the hippocampus to poorer antemortem cognitive function in schizophrenia (Barr et al, 2006b; Young et al, 1998). The functional aspects of SNARE proteins may also be affected in schizophrenia. A study indicated higher SNARE complex formation in the anterior frontal cortex samples obtained from patients who committed suicide (Honer et al, 2002). Investigation of CSF samples obtained from living patients indicated higher than expected levels of SNAP-25, and some correlations with symptom severity (Thompson et al, 2003; Thompson et al, 1999). Genetic studies in humans provide indirect evidence for a role for SNARE proteins in brain function, and in psychiatric illness. Variation in the SNAP25 gene may increase the risk of schizophrenia, contributes to cognitive function in healthy subjects and patients with schizophrenia, is associated with metabolic measures in the hippocampus, antipsychotic treatment response, and with weight gain related to antipsychotic medications (Carroll et al, 2009; Corradini et al, 2009; Gosso et al, 2006; Muller et al, 2005; Musil et al, 2008; Scherk et al, 2008; Spellmann et al, 2008). Variation in STX1A (coding for syntaxin 1a) may be associated with a diagnosis of schizophrenia (Wong et al, 2004).

Animal models indicate that abnormalities of amount or function of SNARE proteins have consequences for neurotransmission and behavior. The coloboma mouse $(\mathrm{Cm} /+)$ has a chromosomal deletion that spans the mouse Snap25 gene, and results in 50\% less SNAP-25 protein in the brain (Hess et al, 1992). These mice have a regionally specific greater level of noradrenalin but lower glutamate, dopamine, and serotonin neurotransmission, delayed acquisition of motor milestones, and hyperactivity as adults (Heyser et al, 1995; Jones et al, 2001; Raber et al, 1997). Hyperactivity in these animals responds to amphetamine treatment (Hess et al, 1996). Microdialysis studies indicate that coloboma mice have high basal levels of synaptic dopamine in the striatum, and increased dopamine release after amphetamine challenge (Fan and Hess, 2007); both these features are similar to schizophrenia (Lyon et al, 2009). Another mutant mouse helps understand the implications of functional changes in SNARE proteins, rather than differences in amount. The mutant mouse blinddrunk $(+/ B d r)$ has motor abnormalities and impaired prepulse inhibition (PPI) (Jeans et al, 2007). Characterization of the molecular basis of this mutation indicated a $\mathrm{T}$-to-C transversion resulting in an isoleucine-to-threonine amino-acid change (Jeans et al, 2007). This change in amino-acid sequence in SNAP-25 results in a greater affinity for the partner SNARE protein syntaxin, greater stability of the SNARE complex, and decreased exocytosis in glutamatergic terminals (Jeans et al, 2007). Interestingly, in the blind-drunk mouse, PPI abnormalities in adulthood are further enhanced if the mice are exposed to prenatal stress (Oliver and Davies, 2009). Treatment of blind-drunk mice with clozapine restored PPI to near normal levels; haloperidol was also moderately effective (Oliver and Davies, 2009). Interestingly, earlier studies of rat brain slice preparations found that administration of dopamine increased SNARE complex formation, an effect that could be blocked by haloperidol (Fisher and Braun, 2000).

This study was designed to investigate SNARE protein levels and SNARE protein-protein interactions in schizophrenia, and to study the effects of antipsychotic drugs on these properties of SNARE proteins in the rat brain. SNARE protein levels were measured in three striatal regions involved in cognitive and limbic circuitry (namely the dorsal caudate (DCd), ventromedial caudate (VMC), and nucleus accumbens (NAc)) (Haber, 2003; Voorn et al, 2004). To determine whether altered SNARE protein-protein interactions were present, we developed a modified sandwich ELISA to measure interactions between syntaxin and SNAP-25. Finally, to determine whether antipsychotic treatment affects SNARE proteins and SNARE complex formation, we performed similar measures in the striatum of rodents treated with haloperidol or clozapine.

\section{MATERIALS AND METHODS}

\section{Human Subjects}

Samples were obtained from the Macedonian/New York State Psychiatric Institute Brain Collection. Tissue collection and screening details can be found in Supplementary Materials and Methods (I). The frozen tissue series consisted of 15 subjects with schizophrenia or other related illness (13 patients with schizophrenia and 2 with schizoaffective disorder) and 13 non-psychiatric comparison subjects (Table 1). All subjects died due to acute causes, and only one had a postmortem interval (PMI) $>24 \mathrm{~h}$. In their lifetime, all patients were exposed to high-potency typical antipsychotics in addition to lower-potency drugs; only three patients were prescribed an atypical antipsychotic (clozapine). Postmortem toxicological analyses detected antipsychotics in only two patients. Caffeine and benzodiazepines were the most frequently detected compounds, and were found in both groups.

Samples were dissected from frozen coronal tissue slabs of the right hemisphere, using a standard human brain atlas (Mai et al, 1997) by a single investigator (WGH). The striatal regions were dissected from the same tissue block at the level of the NAc (approximating slice 12, Mai et al, 1997). The most DCd region was dissected, as well as a medial portion adjacent to the body of the lateral ventricle (VMC) and the gray matter ventral to the internal capsule (NAc).

Formalin-fixed tissues were obtained from four control subjects and four schizophrenia subjects (Supplementary Table S1). Fixed tissue from the VMC was dissected using similar landmarks as for the frozen tissue by a single 
Z

\begin{tabular}{|c|c|c|c|c|c|c|c|c|c|c|c|}
\hline Subject no. & Diagnosis & Sex & Age (years) & $\begin{array}{l}\text { PMl } \\
\text { (hours) }\end{array}$ & $\begin{array}{l}\text { Storage time } \\
\text { (weeks) }\end{array}$ & Brain $\mathrm{pH}$ & Cause of death & $\begin{array}{l}\text { Toxicology } \\
\text { findings }\end{array}$ & Alcohol abuse & Smoker & Antipsychotic exposure \\
\hline । & CTL & M & 53 & 16 & 239 & 5.90 & Homicide & Caf & No & Yes & \\
\hline 2 & CTL & M & 65 & 18 & 68 & 6.76 & Ml & Caf & No & No & \\
\hline 3 & CTL & M & 37 & 7 & 238 & 6.20 & Heart failure (chronic myocarditis) & Negative & No & Yes & \\
\hline 4 & CTL & M & 81 & 22 & 255 & 6.28 & MVA, pulmonary contusion & Caf & No & NA & \\
\hline 5 & CTL & M & 56 & 14 & 106 & 6.40 & Ml & Caf & No & No & \\
\hline 6 & CTL & $\mathrm{F}$ & 41 & 15 & 105 & 5.84 & Homicide, gun shot & Caf & No & Yes & \\
\hline 7 & CTL & M & 36 & 20 & 239 & 6.30 & MVA, cerebral contusion & BZ & No & Yes & \\
\hline 8 & CTL & M & 73 & 21 & 248 & 6.09 & MI & Negative & No & Yes & \\
\hline 9 & CTL & $\mathrm{F}$ & 56 & 19 & 68 & 6.07 & Traffic accident (pedestrian) & BZ, Caf & No & No & \\
\hline 10 & CTL & M & 26 & 15 & 256 & 5.44 & Homicide & Caf & No & Yes & \\
\hline 11 & CTL & $\mathrm{F}$ & 79 & 33 & 238 & 6.00 & $\mathrm{CO}$ intoxication (accidental) & Negative & No & No & \\
\hline 12 & CTL & M & 30 & 6 & 249 & 6.30 & MVA & Negative & No & Yes & \\
\hline 13 & CTL & M & 35 & 10 & 238 & 6.50 & MVA & Caf & No & Yes & \\
\hline Mean, SD & & $3 F: 10 M$ & $51.4,18.8$ & $16.6,7.1^{\mathrm{a}}$ & $196,77^{b}$ & $6.16,0.33$ & & & & 8 Yes, 4 No, I NA & \\
\hline 14 & SCZ & $M$ & 35 & 6 & 218 & 6.40 & lleus & Caf & Yes & Yes & $L, P, C, H, F$ \\
\hline 15 & $\mathrm{sCZ}$ & $\mathrm{F}$ & 45 & 7 & 417 & 6.19 & Pneumonia & Negative & No & Yes & $\mathrm{C}, \mathrm{P}, \mathrm{H}$ \\
\hline 16 & SA & $\mathrm{F}$ & 60 & 9 & 236 & 6.40 & $\mathrm{Ml}$ & $\mathrm{BZ}, \mathrm{CZ}$ & No & No & $L, S, T, F$ \\
\hline 17 & SCZ & M & 45 & NA & 413 & 6.50 & Accidental drowning & BZ, caf & No & Yes & NA \\
\hline 18 & SCZ & M & 58 & 6 & 326 & 6.00 & Pneumonia & Negative & No & Yes & $C, L, T, F, H, C Z$ \\
\hline 19 & SCZ & $M$ & 45 & 8 & 320 & 6.40 & Undetermined & BZ, caf & No & Yes & NA \\
\hline 20 & SCZ & $\mathrm{F}$ & 65 & 6 & 312 & 6.50 & Cardiorespiratory insufficiency & Caf & No & No & $C, L, P, T F, F$ \\
\hline 21 & SCZ & M & 33 & 15 & 390 & 6.50 & Peritonitis & Negative & No & NA & $L, P, F, H$ \\
\hline 22 & SCZ & $\mathrm{F}$ & 77 & 6 & 396 & 5.90 & Ml & $\mathrm{BZ}, \mathrm{AS}$ & No & Yes & $L, P, T, H, F, C Z$ \\
\hline 23 & SCZ & $\mathrm{F}$ & 65 & 7 & 302 & 5.90 & $\begin{array}{l}\text { Cardiorespiratory insufficiency, } \\
\text { cardiomyopathy }\end{array}$ & Negative & No & No & $C, L, P, F$ \\
\hline 24 & SA & M & 53 & 8 & 235 & 6.30 & Ml & $\mathrm{BZ}, \mathrm{CZ}$ & No & Yes & $C, L, P, F, H, C Z$ \\
\hline 25 & SCZ & M & 46 & 14 & 392 & 6.40 & Pancreatitis & Negative & No & Yes & $L, C, P, F, H$ \\
\hline 26 & SCZ & $\mathrm{F}$ & 63 & 7 & 325 & 6.60 & $\mathrm{MI}, \mathrm{TB}$, lobectomy & Negative & No & NA & $C, L, P, F$ \\
\hline 27 & SCZ & M & 61 & 9 & 236 & 6.50 & TB bronchiectasis & Negative & No & No & $L, C, T, H, F$ \\
\hline 28 & SCZ & M & 53 & 15 & 220 & 6.30 & Asphyxia, pharyngeal bolus & Negative & Yes & Yes & $C, P, L, F, P M$ \\
\hline Mean, SD & & $6 \mathrm{~F}: 9 \mathrm{M}$ & $53.6,12.1$ & $8.8,3.2$ & 316,74 & $6.32,0.22$ & & & & 9 Yes, 4 No, 2 NA & \\
\hline
\end{tabular}

Abbreviations: alc, alcohol; AS, asthma medication; BZ, benzodiazapine (available without prescription in Macedonia); C, chlorpromazine; Caf, caffeine; CO, carbon monoxide; CTL, control; CVA, cerebral vascular accident; CZ, clozapine; F, female; F, fluphenazine; H, haloperidol; L, levopromazine; M, male; Ml, myocardial infarction; MVA, motor vehicle accident; NA, not available/unknown; P, promazine; PM, pimozide; PMI,

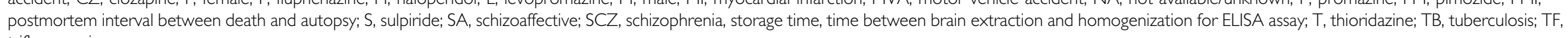
trifluoperazine.

All subjects received an autopsy. Clinical diagnoses were made using the DSM-IV criteria using all available information by a panel of psychiatrists.

aPMI was different between groups $(P=0.001)$.

${ }^{\mathrm{b}}$ Sample storage time was different between groups $(P<0.00 \mathrm{I})$. 
investigator (AJD). Samples were coded to mask investigators to diagnosis and sample characteristics.

\section{Animals and Antipsychotic Drug Administration}

Adult male Sprague-Dawley rats (Charles River, Montreal, Canada) were pair housed, with access to food and water ad libitum. Animals were treated with vehicle or one of the two antipsychotic medications: haloperidol, a high-potency typical antipsychotic agent or clozapine, an atypical antipsychotic, both commonly used in schizophrenia cases (Table 1). Rats were divided into three groups balanced for starting weight (270-320 g range), and administered haloperidol $(1 \mathrm{mg} / \mathrm{kg})$, clozapine $(20 \mathrm{mg} / \mathrm{kg})$, or $\mathrm{pH}$-adjusted saline $(1 \mathrm{ml} / \mathrm{kg})$ daily for 28 days intraperitoneally (Barr et al, 2006a; MacDonald et al, 2005). Haloperidol or clozapine was dissolved in $0.9 \%$ acetic acid/saline, adjusted with $\mathrm{NaOH}$ to $\mathrm{pH}$ 5.0-5.5, and the final volume was adjusted with water to yield a drug concentration of $1 \mathrm{mg} / \mathrm{ml}$. Owing to complications at the injection site, the clozapine group was injected subcutaneously with larger volumes of dilute clozapine $(0.4-0.5 \mathrm{mg} / \mathrm{ml}, 20 \mathrm{mg} / \mathrm{kg}$ ) for the final 16 days. Animals treated with saline and haloperidol gained weight at a similar rate during the 4 weeks, whereas clozapinetreated animals did not gain weight, which is in agreement with findings by others (Albaugh et al, 2006).

Animals were killed by decapitation $24 \mathrm{~h}$ after the final injection. Brains were quickly removed, cooled in artificial cerebrospinal fluid ( $148 \mathrm{mM} \mathrm{NaCl}, 3 \mathrm{mM} \mathrm{KCl}, 1.4 \mathrm{mM} \mathrm{CaCl}_{2}$, $0.8 \mathrm{mM} \mathrm{MgCl}_{2}, 10 \mathrm{mM}$ D-Glucose, $0.8 \mathrm{mM} \mathrm{Na}_{2} \mathrm{HPO}_{4}, 0.2 \mathrm{mM}$ $\mathrm{NaH}_{2} \mathrm{PO}_{4}$ ), and dissected. The brain was cut coronally, at the level of the optic chiasm and again, $3 \mathrm{~mm}$ anterior to this. This produced a 3-mm thick section $0.48 \mathrm{~mm}$ from the bregma (Paxinos and Watson, 1986). The tissue inferior to the ventral striatum was removed. The NAc was then dissected as the most ventral portion of striatum, at the level of the anterior commissure. The remaining caudate/putamen was divided in half to yield medial and lateral portions. A similar dissection protocol was described previously (Meyer and Protopapas, 1985). Regions were dissected bilaterally, frozen rapidly on dry ice, and stored at $-70^{\circ} \mathrm{C}$.

All procedures were approved by the UBC Animal Care Committee and were conducted in accordance with the Canadian Council on Animal Care guidelines.

\section{Antibodies}

We previously prepared monoclonal antibody-producing hybridoma cell lines by fusing B lymphocytes obtained from immunized mice with the non-secreting mouse myeloma cell line NSO. The monoclonal antibodies produced by individual hybridoma cell lines detect SNAP-25 (SP12, IgG subclass), syntaxin ( $\mathrm{SP} 6, \mathrm{IgG}_{1} ; \mathrm{SP} 7, \mathrm{IgG}_{2 \mathrm{~A}}$ ), VAMP (SP10, IgM; SP11, IgG ${ }_{1}$ ), and synaptophysin (EP10, $\operatorname{IgG}_{1}$ ) (Honer et al, 2002, 1997). For each antibody, previously reported characterization studies used the following: immunoblotting to demonstrate single bands at the expected molecular weights for the target antigens, immunocytochemistry to demonstrate staining patterns consistent with a presynaptic pattern of distribution, and studies of reactivity with fusion proteins prepared in bacterial or mammalian cell systems. Additional studies of antibody specificity are described in Supplementary Figure S1. For immunocytochemistry, a polyclonal calretinin antibody (Swant, Bellinzona, Switzerland) was also used. Secondary antibodies included peroxidase-conjugated anti-mouse IgG and IgM (Jackson Immunoresearch Laboratories, West Grove, PA), peroxidase-conjugated anti-mouse $\operatorname{IgG}_{2 \mathrm{~A}}$ (Southern Biotech, Birmingham, AL) and goat anti-mouse or anti-rabbit conjugated to Alexa-488 or Alexa-555 fluors (Molecular Probes, Eugene, OR).

Antibody specificity was confirmed by western blotting (Supplementary Figure S1). For a negative control, we prepared conditioned tissue culture medium by growing the parent mouse myeloma line (NSO) and collecting the medium, which contains the same percentage of fetal bovine serum as was used to grow the antibodysecreting hybridomas, derived by fusing B-lymphocytes with NSO cells.

\section{Direct ELISA Studies}

Frozen samples were rapidly thawed and homogenized in tris-buffered saline (TBS), aliquoted, and stored at $-70^{\circ} \mathrm{C}$. Protein concentrations were determined using a Lowrybased method (DC assay; Bio-Rad, Mississauga, ON). Samples were diluted to a standard concentration for the ELISA, then all were diluted in duplicate on the ELISA plate over a 1-128-fold range.

For these series of studies, hybridoma cell culture supernatants prepared in our laboratory were used as the source of antibodies. These tissue culture supernatants do not contain any other mouse immunoglobulin, which could result in increased nonspecific background signal in the ELISA. This is in contrast to many commercial monoclonal antibodies prepared from mouse ascites fluid, which can contain nonspecific mouse immunoglobulin. The tissue culture supernatants contain fetal bovine serum, and small amounts of bovine immunoglobulin are present. Secondary antibodies specific for mouse immunoglobulin, with minimal cross-reactivity with bovine or human immunoglobulin were used. We also prepared tissue culture supernatants by growing the non-secreting parent myeloma line NS0 under the same culture conditions and fetal bovine serum concentration used to grow the antibody-secreting hybridomas. Substitution of the NS0 conditioned-tissue culture supernatant for antibody-containing supernatant was used as a negative control in the ELISA.

Assays were performed using previously published protocols (Beasley et al, 2005; Honer et al, 2002). SNARE proteins were detected by incubating with SP12 ( $\alpha$-SNAP$25)$, SP6 ( $\alpha$-syntaxin), or SP10 ( $\alpha$-VAMP) diluted (in ratios of $1: 10,1: 10$, and $1: 5$, respectively) in $5 \%$ milk/TBS. On the basis of human sample data, modal values for the linear range of antigen detection (after log transformation) were 64- (SNAP-25), 32- (syntaxin), and 8-fold (VAMP). Immunoreactivity was compared between samples as the amount of protein required to yield a fixed optical density within the linear range. Each experiment was performed twice and the mean value was calculated for each sample.

Samples were assayed twice, on separate days, with runto-run correlations (Pearson's $r$ ) $\geqslant 0.8$ for each measure. Each plate also contained a reference sample, which was not part of the study sample set. The multiple replicates of 
reference samples also allowed calculation of variability in the assays within a sample run. The intra-run coefficient of variation (SD for reference samples divided by mean of reference samples) was $\leqslant 10 \%$ for all runs.

\section{Capture ELISA}

The amount of syntaxin interacting with SNAP-25 was measured using a modified sandwich ELISA. Assay development and validation is detailed in Supplementary Materials and Methods (II). Capture and primary detection mouse monoclonal antibodies, which were free of nonspecific mouse immunoglobulin, were prepared from tissue culture supernatants as described above.

To measure syntaxin-SNAP-25 complexes, 384-well plates (Nalge Nunc International, Rochester, NY) were first coated with purified SP12 antibody (an $\mathrm{IgG}_{1}$ subclass $\alpha$-SNAP-25, capture antibody, $0.075 \mu \mathrm{g}$ per well). Residual binding sites on the coated plates were then blocked with $5 \%$ milk/TBS. Brain homogenates were diluted over a 12 -fold range in TBS, and incubated overnight at $4{ }^{\circ} \mathrm{C}$ in the antibody-coated plates. The capture SP12 antibody immobilized on the ELISA plate pulled out SNAP-25 from the homogenates, as well as any protein interacting with SNAP-25. After washing, syntaxin bound to SNAP-25 was assayed by incubating with antibody SP7 $\left(\mathrm{IgG}_{2 \mathrm{~A}}\right.$ subclass $\alpha$-syntaxin, primary detection antibody, $1: 10$ ), then with a peroxidaseconjugated secondary antibody specific for mouse $\mathrm{IgG}_{2 \mathrm{~A}}$, and ABTS substrate (KPL, Gaithersburg MA). Negative controls performed on each plate included wells with: (1) all steps with omission of the homogenate, (2) all steps with omission of the primary detection antibody SP7, and (3) all steps with omission of both the homogenate and the primary detection antibody SP7. The optical density signal in the negative control wells was $<0.15$, which was the same as the background signal in an empty well.

Analysis was similar to that of direct ELISA. Immunoreactivity was compared between samples as the amount of protein required to yield a chosen optical density within the linear range (12-fold range, modal value). Intra-run CV determined using a reference sample was $\leqslant 10 \%$ and the run-to-run correlation was $>0.8$. Each experiment was completed twice and the mean value was calculated for each sample. As the amount of captured syntaxin was related to the amount of total SNAP-25 in the sample (Supplementary Materials and Methods (II), Supplementary Figure S4), the raw capture values were normalized to total SNAP-25 as measured in direct ELISA.

\section{Immunohistochemistry}

Colocalization of SNARE proteins in the human striatum was confirmed by confocal microscopy on tissue slices of VMC (demographics presented in Supplementary Table S1). Sections of $30-\mu \mathrm{m}$ thickness were cut using a vibratome. The tissue was stained using previously published protocols (Sawada et al, 2005) with modifications. To reduce autofluorescence, sections were incubated for $15 \mathrm{~min}$ in Sudan Black $(0.3 \%$ in $70 \%$ ethanol) (Sigma-Aldrich, St Louis, MO) before processing. Antigen retrieval was performed for SP7-stained sections only, by heating sections in sodium acetate $\left(200 \mathrm{mM} \mathrm{NaCH}{ }_{3} \mathrm{COO}, \mathrm{pH} 4\right)$ for $10 \mathrm{~min}$ at $95^{\circ} \mathrm{C}$. Primary antibody dilutions were as follows: SP12 1:10, SP7 1:10, SP11 1:10, calretinin 1:500. Sections were incubated with fluorescent secondary antibodies (1:500 dilution) for $1 \mathrm{~h}$ at $37^{\circ} \mathrm{C}$, washed and mounted in $70 \%$ glycerol/TBS.

The degree of autofluorescence was ascertained by including sections processed using culture-conditioned media instead of the primary antibody. These were imaged using identical acquisition parameters used for stained sections of that sample. Fluorophores were reversed in some samples.

A laser scanning confocal microscope (LSM 5 Pascal, Zeiss) with a $63 \times / 1.2$-W C-Apochromat water immersion objective was used. Excitation wavelengths of 488 and $543 \mathrm{~nm}$ were used with 505-530 BP and 585 LP emission filters, respectively. Acquisition parameters were optimized for each image so that signal in each channel was not saturated and images were obtained at a $512 \times 512$ pixel resolution. Image processing (autocontrast, brightness, and cropping) was performed using Photoshop 7.0 (Adobe, San Jose, CA). All confocal microscopy was carried out blinded to the diagnosis.

\section{Statistical Analysis}

Data analysis was performed using JMP 5.0.1 for Macintosh (SAS Institute, Cary, NC) and SPSS 11.0 for Macintosh (SPSS, Chicago, IL). Data were graphed using GraphPad Prism 4 (GraphPad Software., San Diego, CA).

For protein measures, consistency with the normal distribution was assessed by the Shapiro-Wilk tests, and data were $\log _{e}$ transformed where necessary. Equality of variances was confirmed by Levene's and/or BrownForsythe tests. For human studies, two-tailed $t$-tests were used to determine whether the PMI, sample storage time, age, and $\mathrm{pH}$ differed between groups (Table 1). ELISA data values (total protein at a fixed optical density) are inversely related to the amount of target antigen present in a sample. For graphing purposes only, we used a simple algebraic transformation to plot data in an intuitively simpler manner, in which greater values represent greater amounts of the target antigen. This results in no distortion of the distribution of values.

Separate two-way ANOVAs were used to determine the effects of diagnosis and the striatal region for each protein measure. The striatal region was entered as the withinsubjects factor and diagnosis as the between-subjects factor. For animal data, the striatal region was entered as the within-subjects factor and treatment group as the betweensubjects factor. Multivariate F-values are reported. For human data, statistically significant diagnosis-by-region interactions were followed up by F-tests to determine in which region there was a statistically significant difference between the diagnostic groups. Raw $P$-values are reported; statistically significant effects are those that withstand Bonferonni's correction for three comparisons (three striatal regions). For animal data, statistically significant effects were followed up by contrasts to determine which drug treatment group showed statistically significant differences from controls. Significance criteria included Bonferonni adjusted for two comparisons (each of two drugs $v s$ control). 
To determine whether sample characteristics or demographics may account for statistical differences, associations between the protein measure in a given area and PMI, $\mathrm{pH}$, sample storage time, and age were investigated using Pearson's or Spearman's correlations, as appropriate. A similar approach to identifying potential confounding factors has been used by others (Burnet et al, 2008; Narayan et al, 2009).

Additional follow-up analyses were conducted using paired $t$-tests to determine whether the levels of SNARE proteins differed between the striatal regions.

\section{RESULTS}

\section{Human Studies}

As seen in Table 1, PMI was longer in the control group $(t=3.73, \mathrm{df}=25, P=0.001)$ and sample storage time was longer in the schizophrenia group $(t=4.21, \mathrm{df}=26$, $P<0.001)$. Age and $\mathrm{pH}$ did not differ between the groups $(P>0.05)$. After a $\log _{\mathrm{e}}$ transformation, SNAP-25, syntaxin, and VAMP protein measures were normally distributed, except for the DCd in the control group in which two values for syntaxin immunoreactivity were found to be lower than
1.5 times the interquartile range and therefore possible outliers. However, there were no differences in variances between groups. Transformed values were used for all subsequent analyses. The amount of captured syntaxin, normalized to total SNAP-25, was normally distributed, and therefore data were not transformed.

\section{SNAP-25 Protein Levels}

Investigation of SNAP-25 protein levels using ANOVA revealed a significant effect of region $(\mathrm{F}=7.44, \mathrm{df}=2,25$, $P=0.003)$ and a region-by-diagnosis interaction $(\mathrm{F}=4.90$, $\mathrm{df}=2,25, P=0.016$ ). Follow-up analyses indicated a lower amount of SNAP-25 protein in the VMC in schizophrenia, compared with controls (32\% lower; $\mathrm{F}=6.86, \mathrm{df}=1,26$, $P=0.015$ ) (Figure 1a). The SNAP-25 protein level was $25 \%$ lower in the NAc in schizophrenia, although this difference was not significant after Bonferonni's correction $(\mathrm{F}=5.24$, $\mathrm{df}=1,26, P=0.030)$. There were no statistically significant correlations between possible confounding factors $(\mathrm{pH}$, PMI, sample storage time, and age) and SNAP-25 in the VMC (all $P>0.09$ ).
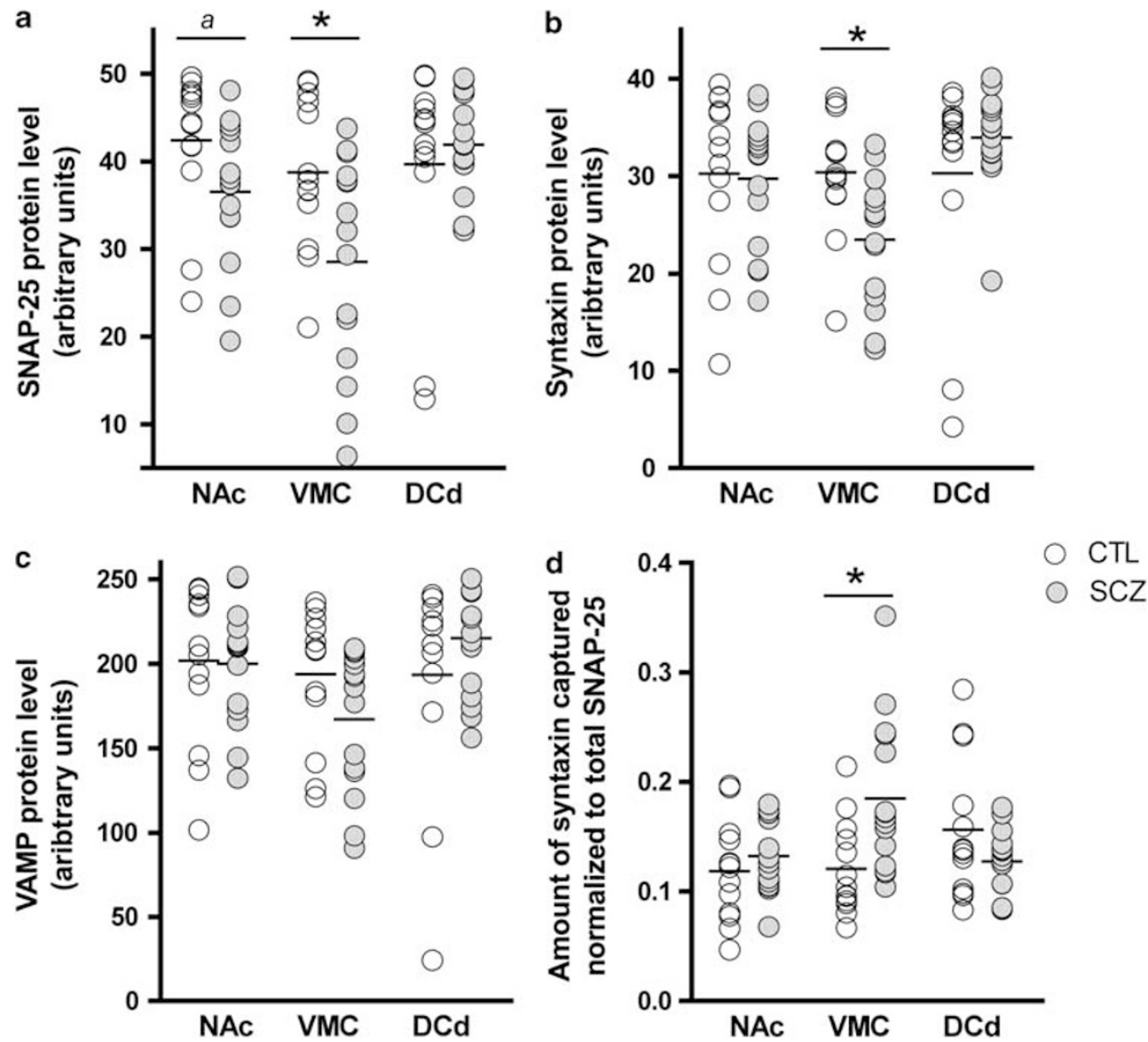

Figure I SNARE protein levels and protein-protein interactions in three human striatal regions. Significant post hoc $F$-tests are indicated $* P<0.05$, Bonferonni-adjusted. Differences that do not survive Bonferonni correction are indicated (a). All three SNARE protein levels were lower in the VMC of subjects with schizophrenia (panels a-c). Syntaxin-SNAP-25 protein-protein interactions were increased in the VMC (d). Horizontal lines indicate group means. Raw (untransformed) but re-scaled values are plotted for the three SNARE measures. NAc, nucleus accumbens; VMC, ventromedial caudate; DCd, dorsal caudate; CTL, controls; SCZ, schizophrenia. 


\section{Syntaxin Protein Levels}

A significant effect of the striatal region $(F=10.50$, $\mathrm{df}=2,25, P<0.001)$ and a region-by-diagnosis interaction $(\mathrm{F}=6.59, \mathrm{df}=2,25, P=0.005)$ were detected for syntaxin protein levels. Syntaxin was lower in the VMC in schizophrenia, compared with controls (26\% lower, $\mathrm{F}=9.18$, $\mathrm{df}=1,26, P=0.006$ ) (Figure $1 \mathrm{~b}$ ). Correlation analysis of syntaxin protein levels in the VMC did not indicate any statistically significant associations between $\mathrm{pH}$, PMI, sample storage time, or age with protein (all $P>0.1$ ).

\section{VAMP Protein Levels}

A significant effect of the striatal region on VAMP protein levels was observed $(\mathrm{F}=10.01, \mathrm{df}=2,25, P<0.001)$. The region-by-diagnosis interaction was also significant $(\mathrm{F}=5.88, \mathrm{df}=2,25, P=0.008)$. Although VAMP levels were $25 \%$ lower in schizophrenia in the VMC, this did not reach statistical significance $(\mathrm{F}=3.84, \quad \mathrm{df}=1,26, \quad P=0.061)$ (Figure 1c). There were no statistically significant associations with possible confounding variables.

\section{SNARE Protein Interactions}

The amount of syntaxin interacting with SNAP-25 (normalized to the total level of SNAP-25 in each sample) was compared between groups and striatal regions. Significant effects of region $(\mathrm{F}=5.89, \mathrm{df}=2,25, P=0.008)$ and a region-by-diagnosis interaction $(\mathrm{F}=6.80, \mathrm{df}=2,25$, $P=0.004)$ were observed. Follow-up F-tests indicated that syntaxin-SNAP-25 interactions were higher in schizophrenia in the $\mathrm{VMC}(\mathrm{F}=8.39, \mathrm{df}=1,26, P=0.008)$ relative to control (Figure 1d). No statistically significant correlations with sample characteristics were identified. We also examined the effect of covarying for the amount of synaptophysin present in the VMC, as an index of the total number of synapses. Synaptophysin levels measured by ELISA were not different in the VMC between schizophrenia and control samples $(t=1.12, \mathrm{df}=26, \quad P=0.27)$. The covariance analysis still showed that syntaxin-SNAP-25 interactions were greater in schizophrenia than in control samples (diagnosis $\mathrm{F}=6.62, \mathrm{df}=1,25, P=0.016$; synaptophysin $\mathrm{F}=7.09$, $\mathrm{df}=1,25, P=0.013)$.

\section{Comparison of Striatal Regions}

To determine how SNARE protein expression varies between the striatal regions, within-subject analyses were performed using paired $t$-tests. As we had identified regionby-diagnosis interactions in the omnibus ANOVA analyses, paired $t$-tests were conducted separately for control and schizophrenia samples. No protein measures showed a significant difference between the striatal areas in the control group (all $P$-values $>0.05$ ), suggesting that SNARE protein levels are homogenous throughout the striatum in control samples. Interestingly, similar pairwise comparisons within the schizophrenia group indicated significant differences between all three striatal regions for SNAP-25, syntaxin, and VAMP (all $P$-values $<0.008$ ) (Table 2).

A similar analysis for capture ELISA data indicated a nominally significant difference in syntaxin-SNAP-25 interactions between the DCd and NAc in the control group $(t=2.28, P=0.042)$, but not between the NAc and VMC, nor between the VMC and DCd. In contrast, in schizophrenia, syntaxin-SNAP-25 interactions were different in the NAc vs VMC, as well as in the VMC vs DCd (all $P$-values $<0.008$ ) but not between the DCd and NAc (Table 2).

\section{Immunocytochemical Studies of SNARE Proteins in the VMC}

As our measurements of SNARE interactions relied on the use of brain homogenates (in which protein localization is disrupted), we confirmed the colocalization of these proteins in the intact human striatum. Stained tissue sections showed no qualitative differences in staining between four control and four schizophrenia subjects. To aid orientation within slices, we double stained for calretinin, a calcium-binding protein present in the cytoplasm of a subset of striatal interneurons. This provided a reference for cell body size and shape that remained unstained by presynaptic markers (Figure $2 \mathrm{a}$ and b). SNAP25 and syntaxin staining appeared diffuse, consistent with their presence not only at synapses but also along axons (Figure 2a-c). Syntaxin staining appeared more uniform than did SNAP-25 staining. VAMP staining appeared more punctate, consistent with predominantly synaptic and

Table 2 Results of Pairwise Comparisons Between Each Striatal area In CTL and SCZ Groups Separately

\begin{tabular}{|c|c|c|c|c|c|c|c|c|c|}
\hline & & \multicolumn{2}{|c|}{ SNAP-25 } & \multicolumn{2}{|c|}{ Syntaxin } & \multicolumn{2}{|c|}{ VAMP } & \multicolumn{2}{|c|}{ SNAP-25 - syntaxin interaction } \\
\hline & & $C T L$ & SCZ & $C T L$ & SCZ & $C T L$ & SCZ & $C T L$ & SCZ \\
\hline \multirow[t]{2}{*}{$\mathrm{Nac}-\mathrm{VMC}$} & $t=$ & -2.08 & -3.11 & -0.485 & -4.56 & -1.03 & -4.53 & -0.194 & -3.77 \\
\hline & $P=$ & 0.06 & 0.0077 & 0.64 & 0.0004 & 0.32 & 0.0005 & 0.85 & 0.0021 \\
\hline \multirow[t]{2}{*}{$\mathrm{DCd}-\mathrm{VMC}$} & $t=$ & -0.599 & -5.37 & -0.174 & -6.62 & -0.513 & -6.12 & 1.78 & -3.76 \\
\hline & $P=$ & 0.56 & $<0.0001$ & 0.87 & $<0.0001$ & 0.62 & $<0.0001$ & 0.10 & 0.0021 \\
\hline \multirow[t]{2}{*}{$\mathrm{DCd}-\mathrm{NAc}$} & $t=$ & 0.931 & -5.08 & -0.519 & -4.63 & 0.497 & -3.34 & 2.28 & -0.538 \\
\hline & $P=$ & 0.37 & 0.0002 & 0.61 & 0.0004 & 0.63 & 0.0048 & 0.04 & 0.60 \\
\hline
\end{tabular}

$T$ - and $P$-values are reported. $P$-values $<0.008$ are statistically significant, correcting for six comparisons within a protein, or the protein-protein interaction. 
a
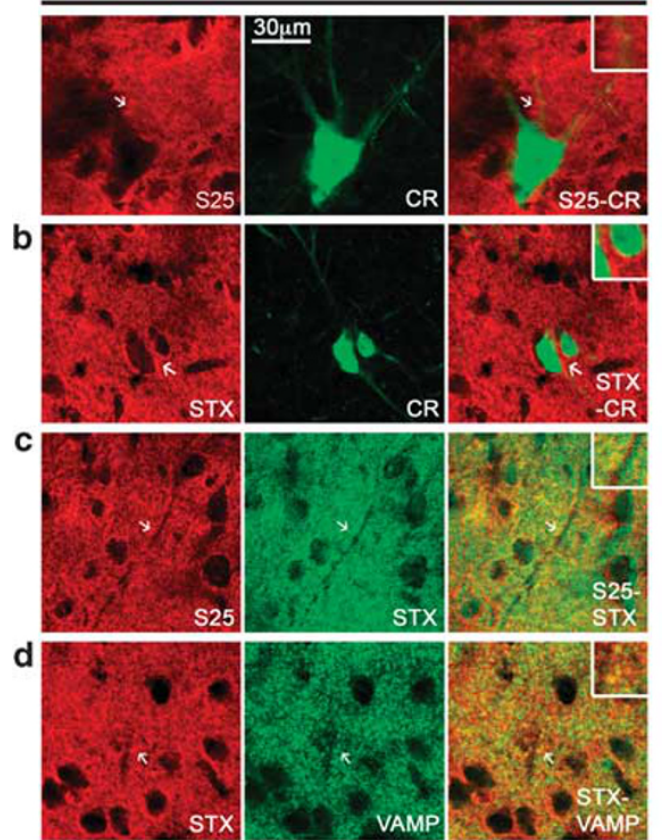

CTL

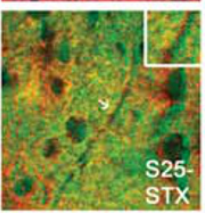

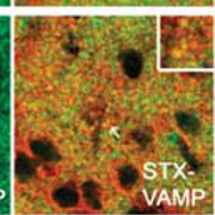
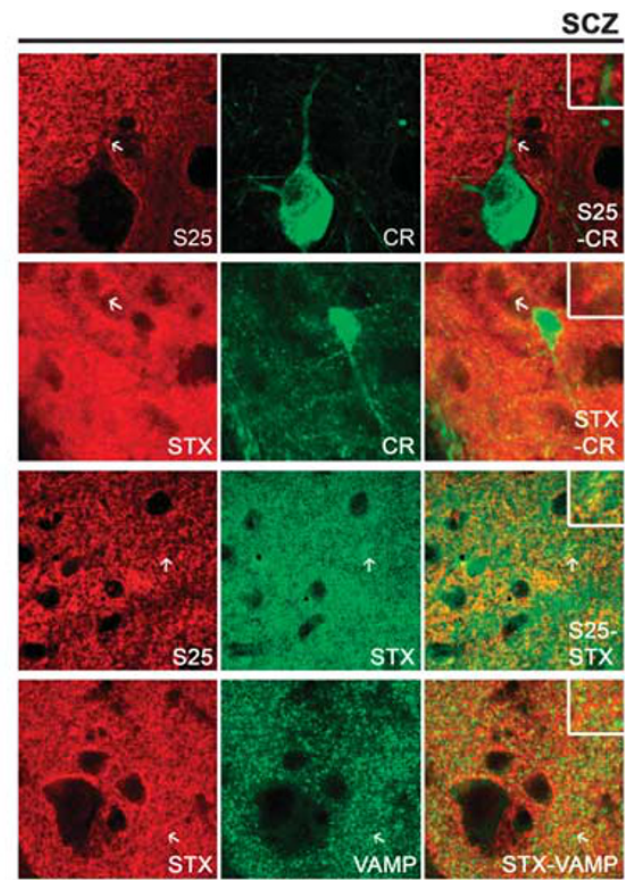

Figure 2 Distribution of SNARE proteins in human VMC. Single-channel images appear in the first two columns, with merged images in the third column. Arrows indicate the region of interest highlighted in the inset. Differences in staining intensity may be the result of slight differences in antibody concentration, antibody penetration, image capture/processing conditions. Calretinin staining appears not to colocalize with presynaptic markers (a and b) and was used as a cell body stain for orientation within the tissue slice. Syntaxin, VAMP, and SNAP-25 show some colocalization with each other (c and d, inset). S25, SNAP25; CR, calretinin; STX, syntaxin.

vesicular locations (Figure 2d). An incomplete colocalization of SNARE proteins was observed.

\section{Antipsychotic Drug Studies}

We examined the possible effects of psychotropic medications present in toxicological analyses at the time of death for the key findings in the VMC. All results remained statistically significant after excluding the two samples with clozapine $(P<0.016)$, or after removing the seven samples with benzodiazepines from the analyses $(P \leqslant 0.017)$. There were no statistically significant differences in any of the primary findings between smokers and nonsmokers.

We analyzed the possible effects of antipsychotic drugs further, by carrying out studies in rats. To improve the normality of the distribution and variances between groups, SNAP-25 protein measures were $\log _{e}$ transformed. For all other measures, untransformed values were used in analyses.

For SNAP-25 protein levels, ANOVA showed a significant effect of treatment $(\mathrm{F}=5.71, \mathrm{df}=2,27, P=0.009)$, as did the striatal region $(\mathrm{F}=6.34, \mathrm{df}=2,26, P=0.006)$, but no interaction effect. Follow-up contrasts indicated that SNAP-25 was increased by a mean amount of $24 \%$ in haloperidol-treated rats compared with saline controls $(\mathrm{F}=11.01, \mathrm{df}=1,27, P=0.003)$, but not different between clozapine-treated animals and controls (Figure 3a).

Drug treatment had a significant effect on syntaxin protein levels $(\mathrm{F}=3.79, \mathrm{df}=2,27, P=0.035)$, but region did not. Syntaxin levels were higher by a mean amount of $18 \%$ in the haloperidol group than in controls $(\mathrm{F}=7.58$, $\mathrm{df}=1,27, P=0.010)$ (Figure $3 \mathrm{~b}$ ).
Drug treatment had a significant effect on VAMP levels $(\mathrm{F}=7.82, \mathrm{df}=2,27, P=0.002)$, as did the striatal region $(\mathrm{F}=7.14, \mathrm{df}=2,26, P=0.003)$. VAMP protein was significantly higher by a mean amount of $16 \%$ in the haloperidol group $(\mathrm{F}=13.38, \mathrm{df}=1,27, P=0.001)$ and by a mean amount of $13 \%$ in the clozapine group $(\mathrm{F}=9.80, \mathrm{df}=1,27$, $P=0.004$ ) (Figure $3 \mathrm{c}$ ), compared with controls.

The amount of syntaxin interacting with SNAP-25 was not significantly different between drug treatment groups, nor between striatal regions (Figure 3d).

As the group-by-treatment interaction was not significant, we investigated the effect of region with the treatment groups combined, for protein measures that showed a significant effect of region. SNAP-25 levels were significantly higher in the lateral than in the medial striatum, or with the NAc (paired $t$-test, all $P$-values $\leqslant 0.009$ ). VAMP levels were higher in the medial striatum than in the NAc or lateral striatum (paired $t$-test, all $P$-values $<0.005$ ). Syntaxin levels were not significantly different between regions.

\section{DISCUSSION}

We observed lower SNARE protein levels in the VMC in schizophrenia, but no significant differences in the NAc or the DCd. These results show that adjacent but functionally distinct brain regions can be differentially affected in schizophrenia. Furthermore, although SNARE protein levels were lower, protein-protein interactions forming SNARE complexes in schizophrenia were greater. Haloperidol administration to rats was associated with higher levels of 

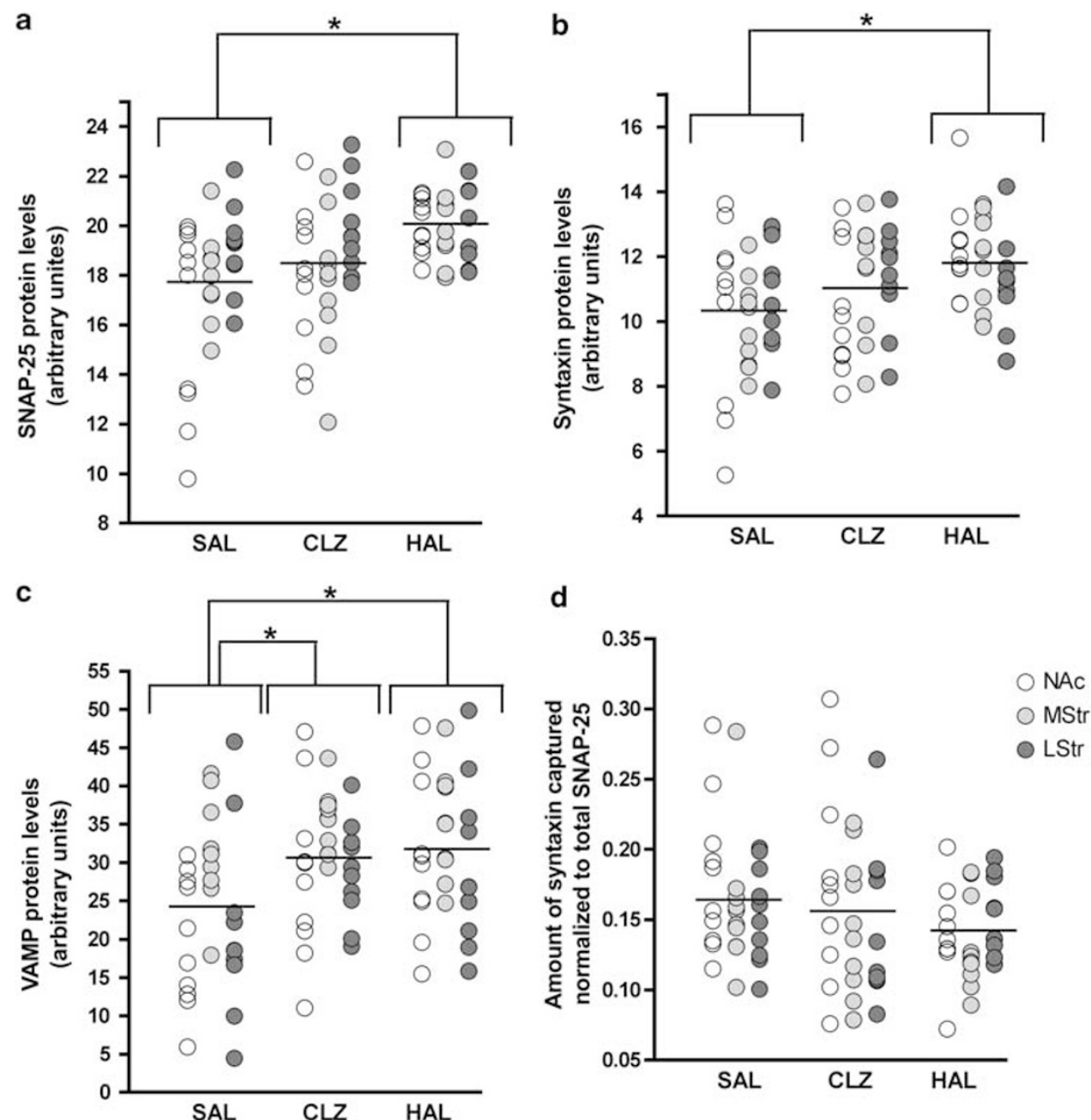

Figure 3 SNARE protein levels $(a-c)$ and interactions $(d)$ in three striatal regions of drug-treated animals. Significant effects of drug treatment $(P<0.05)$ were investigated using contrasts. Statistically significant differences between treatment groups and saline controls are indicated (all $P<0.02$, Bonferonniadjusted). Syntaxin-SNAP-25 protein interactions were not different between groups or striatal regions $(P>0.05)$. Horizontal lines indicate group means (all regions combined). Raw (untransformed) but re-scaled values are plotted for the three SNARE measures.

SNARE proteins, but did not seem to affect protein-protein interactions. Clozapine administration had more selective effects, with only VAMP levels being higher than expected.

\section{SNARE Protein Levels}

Topographically organized corticostriatal and thalamostriatal inputs account for a majority of synapses in the striatum (Haber, 2003). Relevant to our findings, and in the context of patient symptoms, the $\mathrm{VMC}$ receives projections from the medial orbitofrontal cortex, mediodorsal, and medial ventral anterior thalamic nuclei (Haber, 2003), which are areas important for social cognition. In contrast, the NAc receives inputs from the medial cortex and the limbic regions, in addition to the thalamus (MD and VA) (Haber, 2003). Differential SNARE protein changes in these striatal regions could reflect their diverse synaptic inputs. In brain homogenates, the synaptic origin of the measured proteins is unknown. It is possible that not all SNAREs are downregulated in the same synapse in the VMC. Qualitative assessment of double-labeled VMC sections (Figure 2) suggested incomplete colocalization of SNAREs. SNARE isoforms do show some differential distribution in the CNS, supporting this hypothesis (Boschert et al, 1996; RuizMontasell et al, 1996; Trimble et al, 1990). Alternatively, the changes observed herein may be restricted to a specific synapse or terminal type.

Ultrastructural and immunocytochemical studies in the striatum indicate that specific types of synapses may be altered in schizophrenia. Higher numbers of corticostriatal synapses were reported in the anterior caudate in schizophrenia (Roberts et al, 2005b). Alterations may differ between schizophrenia subtypes, with a higher density of excitatory inputs in striatal patches in schizophrenia, but increases in the matrix only in subjects with undifferentiated schizophrenia (Roberts et al, 2008). The relationship of ultrastructural findings to protein levels directly involved in presynaptic function is unclear. Compensatory downregulation of specific SNARE proteins in corticostriatal afferents due to increased synaptic density is one possibility.

Alterations in cell numbers may also contribute to lower SNARE levels. Lower density of cholinergic interneurons was reported in the ventral striatum (corresponding to the 
NAc in our study) in schizophrenia (Holt et al, 2005), lower NOS-positive interneurons in the putamen (Lauer et al, 2005), and lower total neuron number in the caudate (with no alterations in density) (Kreczmanski et al, 2007). We remain cautious in interpreting our findings in the context of such literature, as anatomical locations of the studies might differ, and it is unclear whether SNARE protein distribution is the same in all synapses (Garbelli et al, 2008).

The balance of SNARE proteins between the striatal regions may also be important. In schizophrenia, there is evidence of differences in relationships between striatal compartments (Roberts et al, 2005a), in the balance between excitatory and inhibitory transmission (Lisman et al, 2008), and in relative activity of different brain regions (Whalley et al, 2005). Structural imaging suggests the associative striatum (consistent with VMC and DCd in our study) is most affected in schizophrenia, and also shows the greatest abnormalities of presynaptic functional activity of the dopamine system (Ballmaier et al, 2008; Howes et al, 2009). The subregional distribution of abnormalities of dopamine release in schizophrenia is unknown. Basal- and amphetamine-stimulated dopamine release is higher than normal in the striatum of coloboma mice, where SNAP-25 is low (Fan and Hess, 2007). The low levels of SNAP-25 observed in VMC in our samples could implicate SNAP-25 in the abnormalities of release in patients with schizophrenia.

\section{Syntaxin-SNAP-25 Protein-Protein Interactions}

One approach to assessing the consequences of lower SNAREs is to examine a functional unit - the SNARE complex. In the VMC in schizophrenia, we observed higher SNAP-25-syntaxin interactions, even though levels of SNAP-25 and syntaxin were lower. SNARE complexes were reported to be increased fourfold in rat striatal slices after exogenous dopamine application (Fisher and Braun, 2000). The consequences of greater SNARE complex formation/ stability for neurotransmission may include reduced vesicular release, as shown for glutamatergic terminals in the blind-drunk mouse (Jeans et al, 2007). A greater amount of dopamine release in schizophrenia would be consistent with lower levels of SNAP-25, as observed in coloboma mice (Fan and Hess, 2007). The observed increased SNARE complex formation in VMC in schizophrenia could represent a compensatory mechanism, attempting to dampen overactive dopamine release directly, or indirectly through reduced glutamate release (which normally facilitates striatal dopamine release) (West et al, 2003).

At a molecular level, greater SNARE complex formation could occur if SNAREs have increased affinity for each other. Posttranslational modifications, different isoforms, and changes in amino-acid sequence affect SNARE complex stability and synaptic function (Jeans et al, 2007; Snyder et al, 2006; Sorensen et al, 2003). Accessory factors also modulate SNARE complex formation, stability, and disassembly. Some interacting proteins are already known to be altered in schizophrenia, such as septin-5 and complexins (Pennington et al, 2008; Sawada et al, 2002). Future work is required to determine the possible roles for these factors in the increase in SNARE complexes.

\section{Antipsychotic Drug Effects}

The effects of antipsychotic treatment in rats on striatal SNARE protein levels and protein-protein interactions are different from the findings in schizophrenia tissues. In rats, haloperidol increased levels of all three proteins throughout the striatum, whereas clozapine increased VAMP protein levels. These results are consistent with previous reports in other rat brain areas (Barr et al, 2006a; Sawada et al, 2002) and with ultrastructural studies on the effects of haloperidol in the striatum (Benes et al, 1985; Kerns et al, 1992; Uranova et al, 1991). Our findings do not seem to replicate decreases in synaptic density observed with longer exposure to haloperidol in rodents (Roberts et al, 1995), although compensatory upregulation of SNAREs due to antipsychotic drug-related decreases in synapse number cannot be ruled out. In the latter study, synaptic terminal density returned to normal on 4 weeks of drug withdrawal (Roberts et al, 1995). This scenario may well reflect our human data, as antipsychotic drugs were detectable in only two patients at the time of autopsy. Given a 6.8-week half-life of haloperidol in the human brain (Kornhuber et al, 1999), it seems that many patients were not taking medications for a number of weeks before death. The effects of clozapine seemed to be limited to increasing VAMP levels; SNAP-25 was unchanged. This finding is consistent with the recently reported effects of clozapine on VAMP and SNAP-25 mRNA levels in human neural cell aggregates exposed to these drugs for 3 weeks (Chana et al, 2009). Overall, the greater effect of haloperidol $v s$ clozapine on SNARE proteins could relate to differences in mechanism of drug action. Previous ultrastructural studies described increased overall glutamate labeling in striatal asymmetric synapses associated with both drugs, and additional labeling in a subset of synapses associated with haloperidol only, suggesting different synaptic effects of the two drugs (Meshul et al, 1996).

Greater SNARE complex formation in the VMC was identified in schizophrenia samples in this study. In rats, haloperidol administration was associated with lower SNARE complex formation in the NAc; however, these effects were not statistically significant. One previous study investigated the effects of dopamine and dopamine plus haloperidol on SNARE complex formation in a slice preparation (Fisher and Braun, 2000). Dopamine increased SNARE complex formation, an effect that was blocked by haloperidol. The effects of dopamine antagonists on SNARE complex formation may be different in the presence of elevated dopamine levels.

SNARE proteins were suggested to be targets for the development of therapeutics in psychiatric illness (Lesch and Schmitt, 2002), and modifying SNARE complex formation could be a fruitful strategy. The effects of several classes of psychoactive drugs on SNARE complexes have been studied. Morphine was reported to reduce SNARE complex formation (Xu et al, 2004). Although the antidepressants fluoxetine and reboxetine reduced the levels of all three SNARE proteins, SNARE complex formation was unchanged by these drugs (Bonanno et al, 2005). Several other studies used screening strategies in peptide libraries, and from plant extracts to identify compounds that alter SNARE complex formation (Blanes-Mira et al, 2004; Blanes-Mira et al, 2003; 
Jung et al, 2008; Jung et al, 2009; Riley et al, 2006). Synthetic peptides that modify SNARE complex formation can protect against neurotoxicity in experimental systems (Blanes-Mira et al, 2004), and could also be investigated for activity in animal models of psychiatric illness.

\section{Possible Limitations}

The human brain tissue is invaluable to schizophrenia research, but carries with it inherent limitations. PMI is one possible confounding factor, although the samples that we obtained had shorter PMIs than did the other sample sets (Table 1). As protein levels show little change or decrease with PMI (Siew et al, 2004), the larger PMI of control subjects would lessen protein differences between diagnostic groups. Although $\mathrm{pH}$ has been implicated in the quality of gene expression data (Bahn et al, 2001; Harrison et al, 1995), there is less evidence for an effect of $\mathrm{pH}$ on protein levels (Harrison et al, 1995). Neither of these sample characteristics had an impact on the group differences observed herein. It is possible that differences in life experience (hospitalization, social interaction, active psychosis) could contribute to SNARE alterations, as SNARE expression and complexes can be modified by neuronal activity (Davis et al, 1998; Matveeva et al, 2007). The SNARE protein-protein interactions, observed in this study, were likely formed in vitro, and the relationship to SNARE mechanisms in living patients is uncertain. Overall, our results could indicate synaptic consequences, not mechanisms, of the disorder, providing important information and a possible treatment target. In general, postmortem sample sets are also limited by differences in ethnicity between subjects. Heterogeneity of this kind is minimized in our sample set, procured exclusively in Macedonia. Finally, we recognize that this sample set is relatively small. Replication in a different sample set will strengthen our conclusions.

In summary, alterations in SNARE proteins and SNARE protein-protein interactions provide a possible novel molecular mechanism contributing to abnormal brain function in schizophrenia. These alterations seem to be related to the disease state, and suggest novel targets for the development of therapeutics.

\section{ACKNOWLEDGEMENTS}

This work was supported by the Canadian Institutes of Health Research (MT-14037), the Michael Smith Foundation for Health Research, the MIND Foundation, Neuroscience Canada, the National Institute of Mental Health (MH60877, MH64168, MH62185, MH45212, MH64673), NARSAD, and the Lieber Center for Schizophrenia Research. We thank Ming Yang for technical support.

\section{DISCLOSURE}

The authors declare no conflict of interest.

In addition to their primary employers, Dr Clare Beasley received an honorarium from the Ontario Mental Health Foundation; Dr Alasdair Barr has acted as a consultant to Eli Lilly Canada; Dr J John Mann received grants from GlaxoSmithKline and Novartis; Dr Peter Falkai received fees for professional services from Astra Zeneca, BMS, Eisai, Eli Lilly, Lundbeck, Wyeth, and Jansen-Cilag; Dr William Honer reports receiving consulting fees or sitting on paid advisory boards for the Alberta Heritage Medical Research Foundation, Janssen, Novartis, and AstraZeneca, receiving lecture fees from Partners in Psychiatry, Hotel Dieu Hospital (Kingston), Rush University, the Capital Mental Health Association (Victoria), Université de Montréal, Janssen and AstraZeneca, and educational grant support from Janssen, Eli Lilly and AstraZeneca. Ms Ypsilanti and Li, Drs Thornton, Wong, Rosoklija, Mancevski, Jakovski, Davceva, Ilievski, and Dwork declare that, except for income received from their primary employers, no financial support or compensation was received from any individual or corporate entity over the past 3 years for research or professional service and there are no personal financial holdings that could be perceived as constituting a potential conflict of interest.

\section{REFERENCES}

Albaugh VL, Henry CR, Bello NT, Hajnal A, Lynch SL, Halle B et al (2006). Hormonal and metabolic effects of olanzapine and clozapine related to body weight in rodents. Obesity 14: 36-51.

Bahn S, Augood SJ, Ryan M, Standaert DG, Starkey M, Emson PC (2001). Gene expression profiling in the post-mortem human brain - no cause for dismay. J Chem Neuroanat 22: 79-94.

Ballmaier M, Schlagenhauf F, Toga AW, Gallinat J, Koslowski M, Zoli $\mathrm{M}$ et al (2008). Regional patterns and clinical correlates of basal ganglia morphology in non-medicated schizophrenia. Schizophrenia Res 106: 140-147.

Barr AM, Young CE, Phillips AG, Honer WG (2006a). Selective effects of typical antipsychotic drugs on SNAP-25 and synaptophysin in the hippocampal trisynaptic pathway. Int J Neuropsychopharmacol 9: 457-463.

Barr AM, Young CE, Sawada K, Honer WG (2006b). Relevance of presynaptic proteins to neuropsychiatric disorders. In: Dityatev A, El-Husseini A (eds). Molecular Mechanisms of Synaptogenesis. Springer: Hamburg. pp 391-408.

Beasley CL, Honer WG, Bergmann K, Falkai P, Lutjohann D, Bayer TA (2005). Reductions in cholesterol and synaptic markers in association cortex in mood disorders. Bipolar Dis 7: 449-455.

Benes FM, Paskevich PA, Davidson J, Domesick VB (1985). The effects of haloperidol on synaptic patterns in the rat striatum. Brain Res 329: 265-273.

Blanes-Mira C, Merino JM, Valera E, Fernández-Ballester G, Gutiérrez LM, Viniegra S et al (2004). Small peptides patterned after the N-terminus domain of SNAP25 inhibit SNARE complex assembly and regulated exocytosis. J Neurochem 88: 124-135.

Blanes-Mira C, Pastor MT, Valera E, Fernández-Ballester G, Merino JM, Gutierrez LM et al (2003). Identification of SNARE complex modulators that inhibit exocytosis from an alpha-helixconstrained combinatorial library. Biochem J 375: 159-166.

Bonanno G, Giambelli R, Raiteri L, Tiraboschi E, Zappettini S, Musazzi L et al (2005). Chronic antidepressants reduce depolarization-evoked glutamate release and protein interactions favoring formation of SNARE complex in hippocampus. J Neurosci 25: 3270-3279.

Boschert U, O'Shaughnessy C, Dickinson R, Tessari M, Bendotti C, Catsicas S et al (1996). Developmental and plasticity-related differential expression of two SNAP-25 isoforms in the rat brain. J Comp Neurol 367: 177-193.

Burnet PW, Eastwood SL, Bristow GC, Godlewska BR, Sikka P, Walker $M$ et al (2008). D-amino acid oxidase activity and expression are increased in schizophrenia. Mol Psychiatry 13: 658-660. 
Carroll LS, Kendall K, O'Donovan MC, Owen MJ, Williams NM (2009). Evidence that putative ADHD low risk alleles at SNAP25 may increase the risk of schizophrenia. Am J Med Genet B Neuropsychiatr Genet 1508: 893-899.

Chana G, Lucero G, Salaria S, Lozach J, Du P, Woelk C et al (2009). Upregulation of NRG-1 and VAMP-1 in human brain aggregates exposed to clozapine. Schizophrenia Res 113: 273-276.

Corradini I, Verderio C, Sala M, Wilson MC, Matteoli M (2009). SNAP-25 in neuropsychiatric disorders. Ann NY Acad Sci 1152: 93-99.

Davis S, Rodger J, Stephan A, Hicks A, Mallet J, Laroche S (1998). Increase in syntaxin $1 \mathrm{~B}$ mRNA in hippocampal and cortical circuits during spatial learning reflects a mechanism of transsynaptic plasticity involved in establishing a memory trace. Learn Mem 5: 375-390.

Fan X, Hess EJ (2007). D2-like dopamine receptors mediate the response to amphetamine in a mouse model of ADHD. Neurobiol Dis 26: 201-211.

Fatemi SH, Earle JA, Stary JM, Lee S, Sedgewick J (2001). Altered levels of the synaptosomal associated protein SNAP-25 in hippocampus of subjects with mood disorders and schizophrenia. Neuroreport 12: 3257-3262.

Fisher H, Braun JE (2000). Modulation of the SNARE core complex by dopamine. Can J Physiol Pharmacol 78: 856-859.

Gabriel SM, Haroutunian V, Powchik P, Honer WG, Davidson M, Davies $P$ et al (1997). Increased concentrations of presynaptic proteins in the cingulate cortex of subjects with schizophrenia. Arch Gen Psychiatry 54: 559-566.

Garbelli R, Inverardi F, Medici V, Amadeo A, Verderio C, Matteoli $M$ et al (2008). Heterogeneous expression of SNAP-25 in rat and human brain. J Comp Neurol 506: 373-386.

Gosso MF, de Geus EJC, van Belzen MJ, Polderman TJC, Heutink P, Boomsma DI et al (2006). The SNAP-25 gene is associated with cognitive ability: evidence from a family-based study in two independent Dutch cohorts. Mol Psychiatry 11: 878-886.

Haber SN (2003). The primate basal ganglia: parallel and integrative networks. J Chem Neuroanat 26: 317-330.

Halim ND, Weickert CS, McClintock BW, Hyde TM, Weinberger DR, Kleinman JE et al (2003). Presynaptic proteins in the prefrontal cortex of patients with schizophrenia and rats with abnormal prefrontal development. Mol Psychiatry 8: 797-810.

Harrison PJ (1999). The neuropathology of schizophrenia. A critical review of the data and their interpretation. Brain 122(Pt 4): 593-624.

Harrison PJ, Heath PR, Eastwood SL, Burnet PW, McDonald B, Pearson RC (1995). The relative importance of premortem acidosis and postmortem interval for human brain gene expression studies: selective mRNA vulnerability and comparison with their encoded proteins. Neurosci Lett 200: 151-154.

Hess EJ, Collins KA, Wilson MC (1996). Mouse model of hyperkinesis implicates SNAP-25 in behavioral regulation. J Neurosci 16: 3104-3111.

Hess EJ, Jinnah HA, Kozak CA, Wilson MC (1992). Spontaneous locomotor hyperactivity in a mouse mutant with a deletion including the Snap gene on chromosome 2. J Neurosci 12: 2865-2874.

Heyser CJ, Wilson MC, Gold LH (1995). Coloboma hyperactive mutant exhibits delayed neurobehavioral developmental milestones. Dev Brain Res 89: 264-269.

Holt DJ, Bachus SE, Hyde TM, Wittie M, Herman MM, Vangel M et al (2005). Reduced density of cholinergic interneurons in the ventral striatum in schizophrenia: an in situ hybridization study. Biol Psychiatry 58: 408-416.

Honer WG, Falkai P, Bayer TA, Xie J, Hu L, Li HY et al (2002). Abnormalities of SNARE mechanism proteins in anterior frontal cortex in severe mental illness. Cereb Cortex 12: 349-356.

Honer WG, Falkai P, Young C, Wang T, Xie J, Bonner J et al (1997). Cingulate cortex synaptic terminal proteins and neural cell adhesion molecule in schizophrenia. Neuroscience 78: 99-110.
Honer WG, Young CE (2004). Presynaptic proteins and schizophrenia. Int Rev Neurobiol 59: 175-199.

Howes OD, Montgomery AJ, Asselin MC, Murray RM, Valli I, Tabraham $P$ et al (2009). Elevated striatal dopamine function linked to prodromal signs of schizophrenia. Arch Gen Psychiatry 66: $13-20$.

Jeans AF, Oliver PL, Johnson R, Capogna M, Vikman J, Molnar Z et al (2007). A dominant mutation in Snap25 causes impaired vesicle trafficking, sensorimotor gating, and ataxia in the blinddrunk mouse. Proc Natl Acad Sci USA 104: 2431-2436.

Jones MD, Williams ME, Hess EJ (2001). Abnormal presynaptic catecholamine regulation in a hyperactive SNAP-25-deficient mouse mutant. Pharmacol Biochem Beh 68: 669-676.

Jung CH, Yang YS, Kim JS, Shin JI, Jin YS, Shin JY et al (2008). A search for synthetic peptides that inhibit soluble N-ethylmaleimide sensitive-factor attachment receptor-mediated membrane fusion. FEBS J 275: 3051-3063.

Jung CH, Yang YS, Kim JS, Shin YK, Hwang JS, Son ED et al (2009). Inhibition of SNARE-driven neuroexocytosis by plant extracts. Biotechnol Lett 31: 361-369.

Karson CN, Mrak RE, Schluterman KO, Sturner WQ, Sheng JG, Griffin WS (1999). Alterations in synaptic proteins and their encoding mRNAs in prefrontal cortex in schizophrenia: a possible neurochemical basis for 'hypofrontality'. Mol Psychiatry 4: 39-45.

Kerns JM, Sierens DK, Kao LC, Klawans HL, Carvey PM (1992). Synaptic plasticity in the rat striatum following chronic haloperidol treatment. Clin Neuropharmacol 15: 488-500.

Kornhuber J, Schultz A, Wiltfang J, Meineke I, Gleiter $\mathrm{CH}$, Zochling $\mathrm{R}$ et al (1999). Persistence of haloperidol in human brain tissue. Am J Psychiatry 156: 885-890.

Kreczmanski P, Heinsen H, Mantua V, Woltersdorf F, Masson T, Ulfig $\mathrm{N}$ et al (2007). Volume, neuron density and total neuron number in five subcortical regions in schizophrenia. Brain 130(Pt 3): 678-692.

Lauer M, Johannes S, Fritzen S, Senitz D, Riederer P, Reif A (2005). Morphological abnormalities in nitric-oxide-synthase-positive striatal interneurons of schizophrenic patients. Neuropsychobiology 52: 111-117.

Lesch KP, Schmitt A (2002). Antidepressants and gene expression profiling: how to SNARE novel drug targets. Pharmacogenomics J 2: $346-348$.

Lewis DA, Sweet RA (2009). Schizophrenia from a neural circuitry perspective: advancing toward rational pharmacological therapies. J Clin Invest 119: 706-716.

Lisman JE, Coyle JT, Green RW, Javitt DC, Benes FM, Heckers S et al (2008). Circuit-based framework for understanding neurotransmitter and risk gene interactions in schizophrenia. TINS 31: 234-242.

Lyon GJ, Abi-Dargham A, Moore H, Lieberman JA, Javitch JA, Sulzer D (2009). Presynaptic regulation of dopamine transmission in schizophrenia. Schizophrenia Bull (e-pub ahead of print).

MacDonald ML, Eaton ME, Dudman JT, Konradi C (2005). Antipsychotic drugs elevate mRNA levels of presynaptic proteins in the frontal cortex of the rat. Biol Psychiatry 57: 1041-1051.

Mai JK, Assheuer J, Paxinos G (1997). Atlas of the Human Brain. Academic Press: San Diego, CA. p 328.

Manoach DS, Gollub RL, Benson ES, Searl MM, Goff DC, Halpern E et al (2000). Schizophrenic subjects show aberrant fMRI activation of dorsolateral prefrontal cortex and basal ganglia during working memory performance. Biol Psychiatry 48: 99-109.

Matveeva EA, Vanaman TC, Whiteheart SW, Slevin JT (2007). Asymmetric accumulation of hippocampal 7S SNARE complexes occurs regardless of kindling paradigm. Epilepsy Res 73: 266-274.

McCullumsmith RE, Meador-Woodruff JH (2002). Striatal excitatory amino acid transporter transcript expression in schizophrenia, bipolar disorder, and major depressive disorder. Neuropsychopharmacology 26: 368-375. 
Meshul CK, Bunker GL, Mason JN, Allen C, Janowsky A (1996). Effects of subchronic clozapine and haloperidol on striatal glutamatergic synapses. J Neurochem 67: 1965-1973.

Meyer DK, Protopapas Z (1985). Studies on cholecystokinincontaining neuronal pathways in rat cerebral cortex and striatum. Ann NY Acad Sci 448: 133-143.

Mukaetova-Ladinska EB, Hurt J, Honer WG, Harrington CR, Wischik CM (2002). Loss of synaptic but not cytoskeletal proteins in the cerebellum of chronic schizophrenics. Neurosci Lett 317: 161-165.

Muller DJ, Klempan TA, De Luca V, Sicard T, Volavka J, Czobor P et al (2005). The SNAP-25 gene may be associated with clinical response and weight gain in antipsychotic treatment of schizophrenia. Neurosci Lett 379: 81-89.

Musil R, Spellmann I, Riedel M, Dehning S, Douhet A, Maino K et al (2008). SNAP-25 gene polymorphisms and weight gain in schizophrenic patients. J Psychiat Res 42: 963-970.

Narayan S, Head SR, Gilmartin TJ, Dean B, Thomas EA (2009). Evidence for disruption of sphingolipid metabolism in schizophrenia. J Neurosci Res 87: 278-288.

Nudmamud-Thanoi S, Piyabhan P, Harte MK, Cahir M, Reynolds GP (2007). Deficits of neuronal glutamatergic markers in the caudate nucleus in schizophrenia. J Neural Transm Suppl 72: 281-285.

Oliver PL, Davies KE (2009). Interaction between environmental and genetic factors modulates schizophrenic endophenotypes in the Snap-25 mouse mutant blind-drunk. Hum Mol Genet 18: 4576-4589.

Paxinos G, Watson C (1986). The Rat Brain in Stereotaxic Coordinates. Academic Press: Sydney, Orlando. p 237.

Pennington K, Beasley CL, Dicker P, Fagan A, English J, Pariante $\mathrm{CM}$ et al (2008). Prominent synaptic and metabolic abnormalities revealed by proteomic analysis of the dorsolateral prefrontal cortex in schizophrenia and bipolar disorder. Mol Psychiatry 13: 1102-1117.

Raber J, Mehta PP, Kreifeldt M, Parsons LH, Weiss F, Bloom FE et al (1997). Coloboma hyperactive mutant mice exhibit regional and transmitter-specific deficits in neurotransmission. $J \mathrm{Neu}$ rochem 68: 176-188.

Riley LG, Roufogalis BD, Li GQ, Weiss AS (2006). A radioassay for synaptic core complex assembly: screening of herbal extracts for effectors. Anal Biochem 357: 50-57.

Roberts RC, Gaither LA, Gao XM, Kashyap SM, Tamminga CA (1995). Ultrastructural correlates of haloperidol-induced oral dyskinesias in rat striatum. Synapse 20: 234-243.

Roberts RC, Roche JK, Conley RR (2005a). Synaptic differences in the patch matrix compartments of subjects with schizophrenia: a postmortem ultrastructural study of the striatum. Neurobiol Dis 20: $324-335$.

Roberts RC, Roche JK, Conley RR (2005b). Synaptic differences in the postmortem striatum of subjects with schizophrenia: a stereological ultrastructural analysis. Synapse 56: 185-197.

Roberts RC, Roche JK, Conley RR (2008). Differential synaptic changes in the striatum of subjects with undifferentiated versus paranoid schizophrenia. Synapse 62: 616-627.

Ruiz-Montasell B, Aguado F, Majo G, Chapman ER, Canals JM, Marsal J et al (1996). Differential distribution of syntaxin isoforms $1 \mathrm{~A}$ and $1 \mathrm{~B}$ in the rat central nervous system. Eur $\mathrm{J}$ Neurosci 8: 2544-2552.

Sawada K, Barr AM, Nakamura M, Arima K, Young CE, Dwork AJ et al (2005). Hippocampal complexin proteins and cognitive dysfunction in schizophrenia. Arch Gen Psychiatry 62: 263-272.

Sawada K, Young CE, Barr AM, Longworth K, Takahashi S, Arango $\mathrm{V}$ et al (2002). Altered immunoreactivity of complexin protein in prefrontal cortex in severe mental illness. Mol Psychiatry 7: 484-492.

Scarr E, Gray L, Keriakous D, Robinson PJ, Dean B (2006). Increased levels of SNAP-25 and synaptophysin in the dorsolateral prefrontal cortex in bipolar I disorder. Bipolar Disord 8: 133-143.

Scherk H, Backens M, Zill P, Schneider-Axmann T, Wobrock T, Usher J et al (2008). SNAP-25 genotype influences NAA/Cho in left hippocampus. J Neural Trans 115: 1513-1518.

Siew LK, Love S, Dawbarn D, Wilcock GK, Allen SJ (2004). Measurement of pre- and post-synaptic proteins in cerebral cortex: effects of post-mortem delay. J Neurosci Meth 139: 153-159.

Snyder DA, Kelly ML, Woodbury DJ (2006). SNARE complex regulation by phosphorylation. Cell Biochem Biophys 45: 111-123.

Söllner T, Whiteheart SW, Brunner M, Erdjument-Bromage H, Geromanos S, Tempst P et al (1993). SNAP receptors implicated in vesicle targeting and fusion. Nature 362: 318-324.

Sorensen JB, Nagy G, Varoqueaux F, Nehring RB, Brose N, Wilson $\mathrm{MC}$ et al (2003). Differential control of the releasable vesicle pools by SNAP-25 splice variants and SNAP-23. Cell 114: 75-86.

Spellmann I, Müller N, Musil R, Zill P, Douhet A, Dehning S et al (2008). Associations of SNAP-25 polymorphisms with cognitive dysfunctions in Caucasian patients with schizophrenia during a brief trail of treatment with atypical antipsychotics. Eur Arch Psychiatry Clin Neurosci 258: 335-344.

Thompson PM, Kelley M, Yao J, Tsai G, van Kammen DP (2003). Elevated cerebrospinal fluid SNAP-25 in schizophrenia. Biol Psychiatry 53: 1132-1137.

Thompson PM, Rosenberger C, Qualls C (1999). CSF SNAP-25 in schizophrenia and bipolar illness. A pilot study. Neuropharmacology 21: 717-722.

Thompson PM, Sower AC, Perrone-Bizzozero NI (1998). Altered levels of the synaptosomal associated protein SNAP-25 in schizophrenia. Biol Psychiatry 43: 239-243.

Tost H, Ende G, Ruf M, Henn FA, Meyer-Lindenberg A (2005). Functional imaging research in schizophrenia. Int Rev Neurobiol 67: 95-118.

Trimble WS, Gray TS, Elferink LA, Wilson MC, Scheller RH (1990). Distinct patterns of expression of two VAMP genes within the rat brain. J Neurosci 10: 1380-1387.

Uranova NA, Orlovskaya DD, Apel K, Klintsova AJ, Haselhorst U, Schenk H (1991). Morphometric study of synaptic patterns in the rat caudate nucleus and hippocampus under haloperidol treatment. Synapse 7: 253-259.

Voorn P, Vanderschuren LJ, Groenewegen HJ, Robbins TW, Pennartz CM (2004). Putting a spin on the dorsal-ventral divide of the striatum. Trends Neurosci 27: 468-474.

West AR, Floresco SB, Charara A, Rosenkranz JA, Grace AA (2003). Electrophysiological interactions between striatal glutamatergic and dopaminergic systems. Ann NY Acad Sci 1003: $53-74$.

Whalley HC, Simonotto E, Marshall I, Owens DG, Goddard NH, Johnstone EC et al (2005). Functional disconnectivity in subjects at high genetic risk of schizophrenia. Brain 128(Pt 9): 2097-2108.

Wong AH, Trakalo J, Likhodi O, Yusuf M, Macedo A, Azevedo MH et al (2004). Association between schizophrenia and the syntaxin 1A gene. Biol Psychiatry 56: 24-29.

Xu NJ, Yu YX, Zhu JM, Liu H, Shen L, Zeng R et al (2004). Inhibition of SNAP-25 phosphorylation at Ser187 is involved in chronic morphine-induced down-regulation of SNARE complex formation. I Biol Chem 279: 40601-40608.

Young CE, Arima K, Xie J, Hu L, Beach TG, Falkai P et al (1998). SNAP-25 deficit and hippocampal connectivity in schizophrenia. Cereb Cortex 8: 261-268.

Supplementary Information accompanies the paper on the Neuropsychopharmacology website (http://www.nature.com/npp) 